\title{
FLUJO DE GENES ENTRE FRIJOL COMÚN Y SILVESTRE EN COSTA RICA ${ }^{1}$
}

\author{
Néstor Chaves-Barrantes ${ }^{2}$,Rodolfo Araya-Villalobos ${ }^{2}$, Daniel Debouck $^{3}$
}

\section{RESUMEN}

Flujo de genes entre frijol común y silvestre en Costa Rica. Con el objetivo de analizar el flujo de genes entre frijol común silvestre y cultivado, se determinó el porcentaje de alogamia en condiciones naturales de crecimiento del frijol silvestre y en estación experimental. En el 2004 se evaluó el cruzamiento natural entre frijol silvestre mexicano G23511A (Phaseolus vulgaris L.) y la línea blanca PAN 68, en la Estación Experimental Fabio Baudrit de la Universidad de Costa Rica en Alajuela. Para ello se sembraron dos parcelas experimentales; cada una constó de dos bloques de PAN 68 de 10 surcos (15 m de largo y espaciados 0,6 m). Entre los bloques y en el borde superior de los mismos, se sembraron tres surcos de frijol silvestre como donantes de polen. Se numeraron las hileras y las plantas de cada una en los bloques de frijol blanco. En Quircot de Cartago (área donde crece en forma natural P. vulgaris silvestre), en el 2005 y 2006, se sembraron plantas de frijol comercial (Vainica de Palo) a lo largo de seis sitios junto a las poblaciones de frijol silvestre. En ambas localidades la floración de silvestres y comerciales fue coincidente. Se cosechó toda la semilla de los ensayos y se germinó en bandejas, determinando el porcentaje de alogamia por medio del color morado del hipocotilo, indicativo de aquellas plántulas cruzadas. En Alajuela el porcentaje de cruza varió entre 0,007 y $0,028 \%$; mientras que en Quircot, entre 0 y 0,199\%.

Palabras clave: Alogamia, Phaseolus vulgaris silvestre, cruzamiento natural, abejas, Bombus spp.

\begin{abstract}
Gene flow between wild common bean and cultivated cultivars in Costa Rica. In order to study gene flow between common wild and cultivated cultivated bean, the rate of allogamy was estimated in a location where wild common bean grows naturally and at an experimental station. In 2004, natural outcrossing between wild Mexican bean G23511A (Phaseolus vulgaris L.) and white cultivar PAN68 was estimated at Fabio Baudrit Experimental Station of the University of Costa Rica in Alajuela. Two experimental plots were sown; each one had two blocks of ten rows of PAN68 (15m long and 0,6m spaced). Between blocks and at their upper border, three rows of wild Mexican common bean were sown as pollen donors. Each of the rows and plants in the white blocks was numbered. In 2005 and 2006 in Quircot, Cartago, where wild common bean grows naturally, plants of common bean (Vainica de Palo) were sown in six locations adjacent to wild common bean populations. In both locations, flowering of wild and cultivated bean was coincident. All seeds from assays were harvested and germinated in seedling trays, estimating the rate of allogamy through the color of the hipocotyl (purple), which indicates what seedlings were crossed. In Alajuela, natural crossing ranged from 0,007 to $0,028 \%$, whereas in Quircot from 0 to $0,199 \%$.
\end{abstract}

Key words: Allogamy, wild Phaseolus vulgaris, natural outcrossing, honybees, Bombus spp.

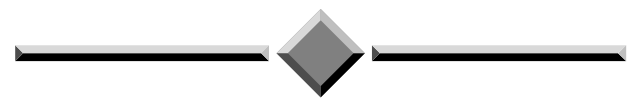

\footnotetext{
Recibido: 29 de junio, 2009. Aceptado: 16 de noviembre, 2009. Trabajo financiado por el German Federal Ministry for Economic Cooperation and Development (BMZ), el Centro Internacional de Agricultura Tropical (CIAT) y la Universidad de Costa Rica (Proyecto VI 736-A1-553).

2 Programa de Leguminosas, Estación Experimental Fabio Baudrit Moreno, Universidad de Costa Rica. Alajuela, Costa Rica. Apdo. postal 400-4060 Alajuela, Costa Rica.nfchaves@gmail.com; Apdo. postal 2645-3000 Heredia, Costa Rica. avillalo2005@hotmail.com

3 Unidad de Recursos Genéticos, Centro Internacional de Agricultura Tropical (CIAT). Cali, Colombia. d.debouck@cgiar.org
} 


\section{INTRODUCCIÓN}

En Costa Rica existe gran variabilidad genética de especies del género Phaseolus y en los últimos 20 años se han identificado 22 poblaciones de $P$. vulgaris silvestre (Debouck et al. 1989, Araya et al. 2001, Araya y Debouck 2003, González et al. 2004). Hay sitios, como Quircot (provincia de Cartago), donde conviven varias especies silvestres de Phaseolus cerca de los campos comerciales de frijol común; por lo que se han encontrado evidencias de flujo natural de genes entre formas cultivadas, y entre formas cultivadas y silvestres de $P$. vulgaris (Araya y Debouck 2003).

Por ser el frijol común una especie autógama, normalmente la incidencia de cruzamiento natural es muy baja (Bliss 1980, León 1987); sin embargo, se han observado grandes diferencias en ensayos llevados a cabo en diferentes localidades y países. En el caso de flujo de genes entre variedades comerciales y frijol silvestre se encontró una alogamia promedio de 1,5\% en Cerrito, Valle, Colombia (Triana et al. 1993) y de 20 a $55 \%$ en Sierra Norte, Puebla, México (Gepts et al. 2000).

Por otro lado, el cruzamiento natural entre cultivares comerciales se ha estudiado en países como México, Puerto Rico, Estados Unidos, Brasil, Etiopía, España, Venezuela y Costa Rica. La alogamia determinada varió desde 0 hasta $66,8 \%$ en ensayos realizados en Estados Unidos (Tucker y Harding 1975, Wells et al. 1988), pero en la mayoría de los casos, con excepción de Puerto Rico, donde Brunner y Beaver (1989) obtuvieron un 39,3\%; los porcentajes máximos fueron bajos. Por ejemplo 7,4\% en México (Miranda 1971); 4,8 \% en Etiopía (Stoetzer 1984); 2,25 \% en Brasil (Regina et al. 2000); 0,74\% en España (Ferreira et al. 2000) y $0,49 \%$ en Venezuela (Ortega 1974).

En Costa Rica, el flujo de genes en el frijol común fue estudiado por Alan y Moh (1966), quienes encontraron una alogamia máxima de $0,20 \%$ en Alajuela; por Pinchinat (1967) citado por Ortega (1974) quien obtuvo un $0,10 \%$ de cruzamiento natural y por Chaves et al. (2003 y $\left.2007^{4}\right)$ quienes determinaron un promedio de $0,029 \%$ de alogamia en ensayos realizados en Alajuela y Fraijanes del 2002 al 2006. En un ensayo

4 Chaves, N. 2007. Flujo de genes en frijol. Alajuela, Costa Rica. Programa de Leguminosas, Estación Experimental Fabio Baudrit. Comunicación personal. preliminar en Quircot, se sembraron variedades criollas de frijol junto a las aéreas naturales de crecimiento del frijol silvestre; obteniéndose un cruzamiento natural que varió entre 0 y 16,36 \% (Araya et al. 2004).

Tanto en el flujo de genes entre cultivados y entre éstos y silvestres, se presentan grandes diferencias en los datos indicados por los autores; ésto se debe en su mayor parte a aspectos metodológicos y a factores ecológicos propios de los sitios donde se realizaron los trabajos.

Dado el nivel de cruzamiento natural y flujo de genes entre plantas de frijol, es importante determinar el impacto potencial futuro que podría tener la introducción de plantas transgénicas de Phaseolus y sus implicaciones en el germoplasma de $P$. vulgaris de uso comercial y silvestre. También es importante considerar el impacto de la alogamia sobre la industria de semillas, pues si los niveles de cruzamiento son altos, se puede afectar la producción de semilla genéticamente pura. El objetivo del presente trabajo fue determinar el porcentaje de alogamia entre un frijol común silvestre y uno cultivado.

\section{MATERIALES Y MÉTODOS}

Para estudiar el flujo de genes entre frijol común silvestre y cultivado, se determinó el porcentaje de alogamia tanto en una estación experimental como en condiciones naturales de crecimiento del frijol silvestre. La investigación se llevó a cabo en Costa Rica, entre setiembre del 2003 y enero del 2004 en la Estación Experimental Fabio Baudrit (EEFBM) ubicada en Alajuela $\left(10^{\circ} 01^{\prime} \mathrm{N} ; 84^{\circ} 16^{\prime} \mathrm{O} ; 840 \mathrm{msnm}\right)$, y entre setiembre del 2005 y enero del 2006, y setiembre del 2006 y febrero del 2007 en Quircot, Cartago $\left(09^{\circ} 54^{\prime} \mathrm{N}\right.$; $83^{\circ} 56^{\circ} \mathrm{O}$; $1.540 \mathrm{msnm}$ ).

En la localidad de Alajuela se sembró la línea de frijol blanco PAN 68 [BAT 338 x G 3645-6-1CM (5-C)-M, hábito tipo II, grano pequeño y opaco] y el frijol silvestre de origen mexicano G23511A, ambos contrastantes para la característica del color del hipocotilo y de la flor: el silvestre con hipocotilo morado (carácter dominante) y flores lilas, y la línea con hipocotilo verde (carácter recesivo) y flor blanca. En Quircot se trabajó con las poblaciones naturales de frijol silvestre y se sembró junto a ellas el cultivar Vainica de Palo (variedad acriollada de la zona, con hipocotilo verde, hábito tipo IV, flor blanca y grano 
amarillo). Esta condición permitió utilizar el color del hipocotilo como marcador morfológico, para identificar las progenies originadas de la cruza entre ambos tipos de frijol, y así diferenciarlas de las provenientes de la autopolinización del genotipo con hipocotilo verde.

Se utilizó el color del hipocotilo, ya que es una característica dominante, estable e independiente del ambiente; además de que puede distinguirse fácilmente en los primeros estadíos de desarrollo de la planta (Alan y Moh 1966). El color del hipocotilo está determinado por un solo locus genético $(\mathrm{P} / \mathrm{p})$, así el homocigoto recesivo (pp) es verde (sin color) mientras que el genotipo dominante (PP) y el heterocigoto (Pp) tienen hipocotilos morados (Ibarra et al. 1996).

En Alajuela se sembraron dos parcelas experimentales, cada una constó de dos bloques de PAN 68 de 10 surcos de $15 \mathrm{~m}$ de largo y espaciados 0,6 m. Entre los bloques y en el borde superior de los mismos, se sembraron tres surcos de frijol silvestre mexicano como donantes de polen y se colocaron tutores de $2 \mathrm{~m}$ de alto para ayudar en su establecimiento. Se llevó un registro de las fechas de inicio de las principales etapas fenológicas del cultivo, en especial del período de floración, durante el cual se observó la actividad y tipo de polinizadores que visitaron la parcela, así como la dirección del viento predominante. Las parcelas del ensayo se ubicaron en un lugar completamente aislado para evitar contaminación con polen proveniente de otras siembras de frijol cercanas.

Se cosecharon todas las plantas de los bloques de PAN 68, numerando las hileras de uno a diez en el bloque (A) y de once a veinte en el otro bloque (B). A su vez, se numeraron las plantas de cada hilera (Figura 1). Con base en la numeración efectuada en campo, se procedió a determinar la ubicación aproximada de cada planta donde se dio un evento de cruza y de la progenie resultante de dicho cruce, dentro de la parcela del ensayo.

Las plantas secas se desgranaron manual e individualmente, y las semillas de cada una se contaron con ayuda de un contador automático (Multi Auto Counter, Model DC1, No. 03031, Everwell Corporation). Las semillas se almacenaron en sobres de papel cerrados e identificados. Luego, se pusieron a germinar en bandejas en una casa de mallas; cada grupo de semillas se identificó por medio de una paleta plástica con el número de planta e hilera correspondientes. Se empleó suelo previamente mezclado con granza de arroz en

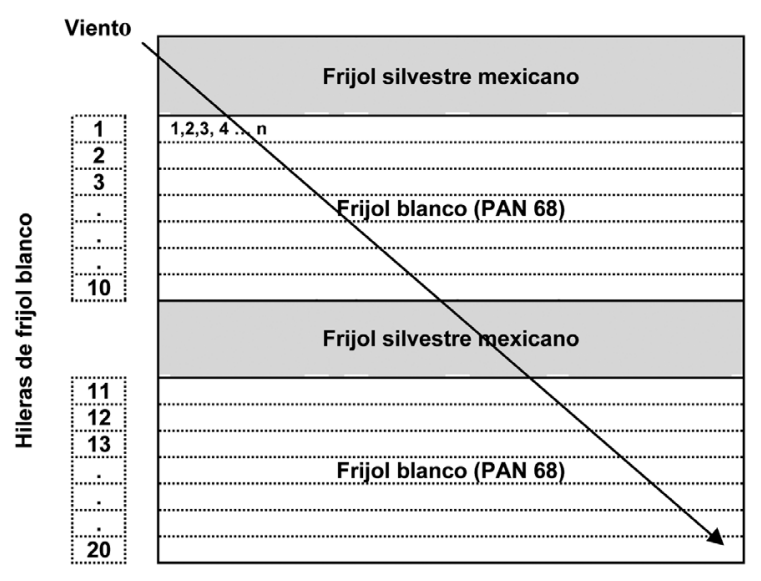

Figura 1. Esquema de siembra de las parcelas y de numeración de las plantas en el campo. EEFBM, Alajuela. 2007.

proporción de 3:1 como sustrato y se colocó una semilla por celda. El sustrato se trató con benomil ( $80 \mathrm{~g}$ de i.a./161) adicionado con bomba de espalda. Entre los siete y nueve días después de la siembra, cuando las plántulas tenían ocho centímetros de altura, se evaluó el color del hipocotilo y la venación de las hojas cotiledonares, para determinar si presentaban cruza o no. Cuando se encontró una planta cruzada se trasplantó a un pote y se llevó a cosecha; las que no presentaron cruce se desecharon.

En Quircot de Cartago el ensayo consistió en ubicar plantas del cultivar Vainica de Palo a lo largo de seis sitios junto a las poblaciones de frijol silvestre (Figura 2). La selección del cultivar comercial de grano de color amarillo, se basó en tres criterios: su hábito trepador, su color de hipocotilo (verde) y su adaptación a altitudes entre los 1.500 y 2.000 msnm.

Las semillas de Vainica de Palo se germinaron en bandejas con peat moss (Plug Mix Perlite VJ PMP 4CF) en la Estación Experimental Fabio Baudrit en Alajuela y se llevaron a Quircot a los 15 días de edad. Ahí se transplantaron a los sitios de siembra, donde previamente se había observado frijol silvestre en crecimiento vegetativo. A la par de cada plántula transplantada se colocaron dos tutores de bambú para ayudar a su establecimiento.

En el año 2005 se sembraron 1.000 plántulas del frijol Vainica de Palo, 500 el 28 de setiembre y 500 el 20 de octubre. Se trató de abarcar un período de tiempo lo suficiente amplio, para que coincidieran las 


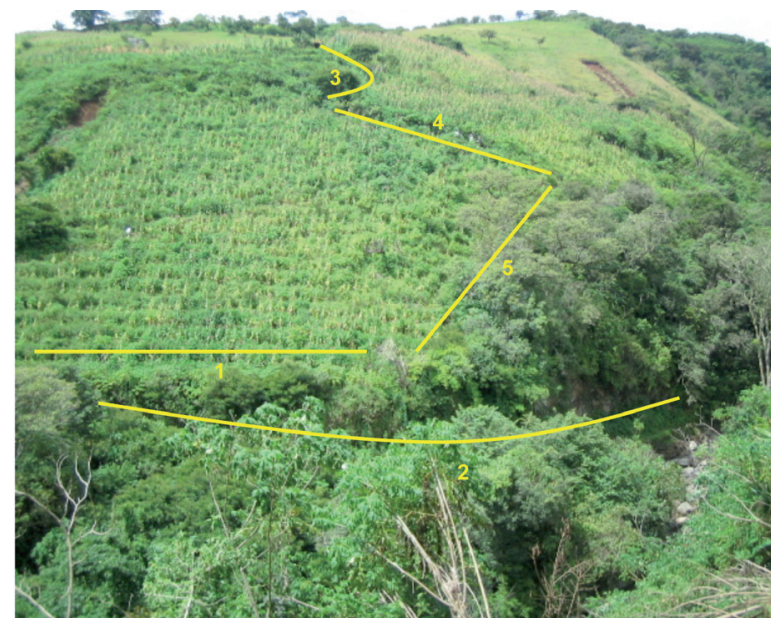

Figura 2. Ubicación de los sitios de siembra del frijol Vainica de Palo en la finca de la Cooperativa Rosales (punto 6 fuera de la imagen). Quircot, Cartago, Costa Rica. 2007.

floraciones de ambos tipos de frijol. En el 2006, se sembraron 500 plántulas del frijol Vainica de Palo el 13 de octubre y otras 500 el 27 del mismo mes.

La cosecha se realizó por sitio de siembra. La determinación del flujo de genes, se basó en la evaluación del color del hipocotilo. Para ello, los grupos de semillas cosechados por sitio de siembra, se germinaron en bandejas; pero a diferencia del ensayo anterior, se empleó como sustrato peat moss. Cuando se encontró una plántula cruzada se trasplantó a un pote en casa de mallas para llevarla a cosecha.

Tanto en Alajuela como en Quircot, el cruzamiento natural se determinó al obtener la proporción de plántulas que germinaron con hipocotilo morado con respecto al total de plántulas germinadas.

\section{RESULTADOS Y DISCUSIÓN}

Para ambas parcelas experimentales en Alajuela y en ambas épocas de siembra en Quircot, hubo sincronía entre las floraciones del cultivar comercial y del frijol silvestre. La sincronía en la floración es un aspecto importante, que garantizó que la receptividad de los estigmas de las flores de la variedad de hipocotilo claro y la viabilidad del polen de las flores del silvestre ocurrieran al mismo tiempo.
Ambos frijoles silvestres iniciaron su floración estimulados por la pequeña variación que se da en la duración del día en Costa Rica, acortándose alrededor de una hora desde el 21 de junio (12,5 h) hasta el 21 de diciembre (11,5 h) (Gutiérrez et al. 1997). Usualmente los frijoles silvestres entran en floración en la primera o segunda semana de noviembre y esta etapa fenológica se extiende alrededor de seis semanas. Con base en esta información, se programó la siembra del frijol PAN 68 en la EEFBM, para que su floración coincidiera con la del silvestre. Así, el frijol PAN 68 de la primera época de siembra floreó del 07/11/04 al 24/11/04 y el de la segunda época de siembra del 14/11/04 al 02/12/04, mientras que el silvestre mexicano lo hizo del 07/11/04 al 15/12/04. En el caso de Quircot, la variedad Vainica de Palo respondió al mismo estímulo que el frijol silvestre, por lo que sus floraciones fueron coincidentes en ambos años.

En la EEFBM varios tipos de insectos visitaron las parcelas experimentales, pero los observados con mayor frecuencia durante el período de floración fueron las abejas (Hymenoptera, Apis spp.), que se indican como uno de los polinizadores más importantes en frijol por su adaptación a la estructura floral de esta planta (Free 1966). También fue posible observar con gran frecuencia trigonas (Trigona spp) y en forma ocasional chiquizás (Bombus spp), que aunque son conocidos por su eficiencia como agentes polinizadores, mostraron una marcada preferencia por las flores del frijol silvestre. Otros insectos que visitaron las parcelas fueron las mariquitas (Coleoptera: Coccinellidae) y las mariposas (Lepidoptera); sin embargo, éstos son visitantes ocasionales e inclusive algunos insectos del orden Lepidoptera se consideran ladrones de polen y néctar, pues no desencadenan los mecanismos de transferencia polínica. En Quircot, el principal polinizador observado fue el chiquizá, cuya actividad y número de individuos fue importante durante el primer año, en relación con el segundo. También se observaron abejas, pero en poca cantidad en ambos períodos.

En Alajuela se obtuvo un cruzamiento natural que varió desde 0,007 hasta $0,028 \%$ y cuyos eventos se concentraron principalmente en uno de los bloques (A) de ambas parcelas experimentales (Cuadro 1). No se logró observar alguna distribución espacial determinada de las cruzas (Figura 3), contrario a lo observado en los ensayos para determinar la alogamia entre variedades comerciales, donde las plántulas cruzadas provinieron de las hileras más cercanas a la fuente de polen (Chaves et al. 2003, Chaves ${ }^{4}$. 
Cuadro 1. Porcentaje de alogamia en el ensayo de flujo de genes entre frijol blanco y frijol silvestre mexicano. EEFBM, Alajuela, Costa Rica. 2004.

\begin{tabular}{lcc}
\hline Indicador & Parcela $\mathbf{1}$ & Parcela 2 \\
\hline Semillas & 73509 & 52340 \\
Germinación (\%) & 92,37 & 76,00 \\
Plántulas germinadas & 67901 & 39779 \\
Plántulas cruzadas & 5 & 11 \\
Alogamia Bloque A (\%) & 0,012 & 0,046 \\
Alogamia Bloque B (\%) & 0,003 & 0,006 \\
Alogamia total (\%) & $\mathbf{0 , 0 0 7}$ & $\mathbf{0 , 0 2 8}$ \\
\hline
\end{tabular}

En Quircot se obtuvo una alogamia de 0,199\% en el 2006, mientras que en el 2007 no se obtuvo cruzamiento (Cuadro 2 y 3). Durante el primer año, se observó gran cantidad de chiquizás rondando el ensayo y se rescató mayor cantidad de semilla, por lo que se pudo medir con mayor certeza el cruzamiento que se presentó entre el frijol silvestre costarricense y el cultivar de frijol de hipocotilo claro. Con respecto a ésto, los porcentajes de cruza natural más altos (sitios dos y cinco) coincidieron con el área donde hubo mayor cantidad de plantas de frijol silvestre, que se ubicaba en medio de ambos sitios y que aumentó las posibilidades de cruzamiento. Durante el segundo año se tuvo problemas con el establecimiento de las plantas de Vainica de Palo debido a la ausencia de lluvias. Esto ocasionó que se rescataran pocas semillas y al ser tan bajos los porcentajes de cruzamiento natural, talvez no se logró captar el flujo de genes que se pudiera haber presentado en ese año. Además, hubo un uso más intenso de agroquímicos pues se tenía frijol en monocultivo en los alrededores, lo que pudo ocasionar una merma en el número de polinizadores que visitaron el ensayo.

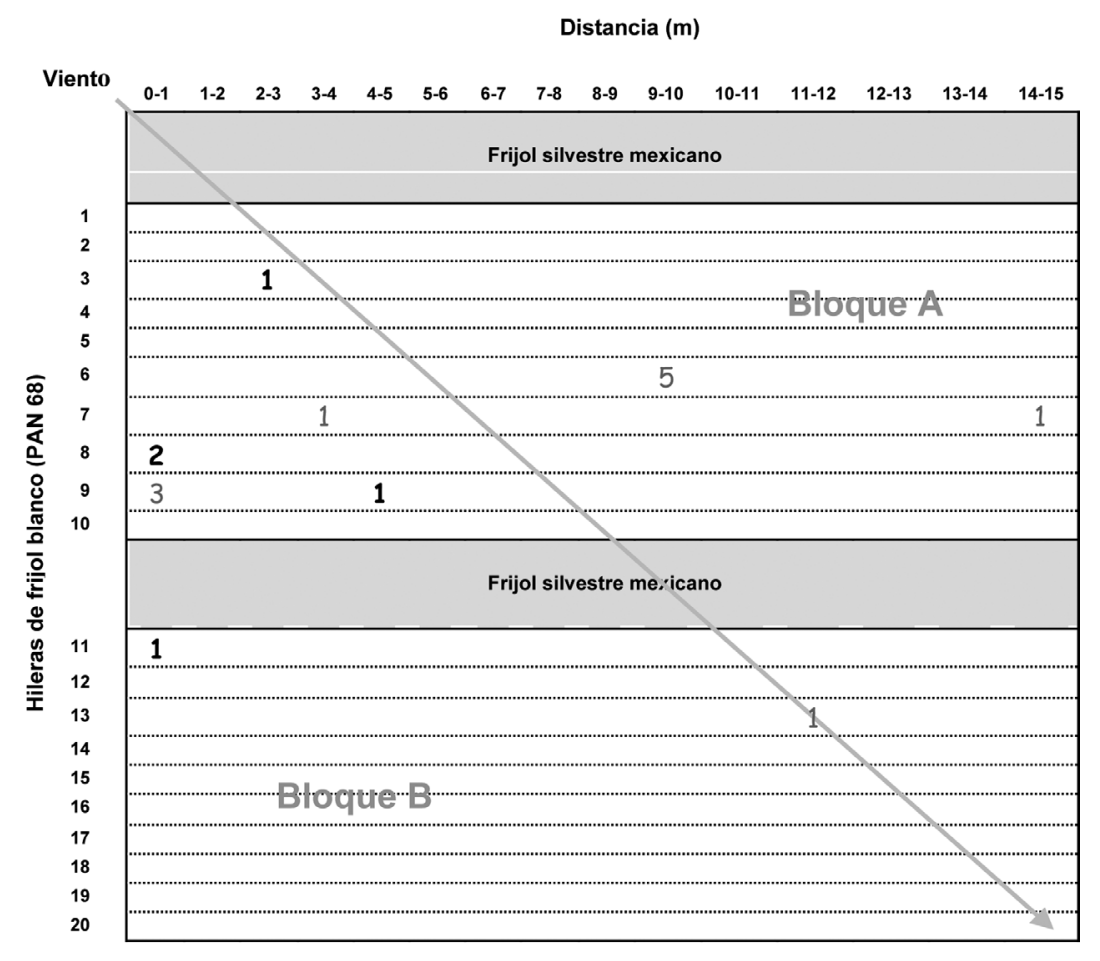

Figura 3. Ubicación espacial aproximada de las plantas donde hubo cruzamiento y número de plántulas con hipocotilo morado generadas a partir de las semillas de cada planta (cruzas por metro); color negro (parcela 1) y color gris (parcela 2). EEFBM, Alajuela, Costa Rica. 2004. 
Cuadro 2. Porcentaje de alogamia en el ensayo de flujo de genes entre frijol blanco y frijol silvestre costarricense. Quircot, Cartago, Costa Rica. 2006.

\begin{tabular}{|c|c|c|c|c|c|c|c|}
\hline \multirow[t]{2}{*}{ Sitio* } & \multirow[t]{2}{*}{ Semillas } & \multirow{2}{*}{$\begin{array}{c}\text { Plántulas } \\
\text { germinadas }\end{array}$} & \multicolumn{2}{|c|}{ Hipocotilo } & \multirow{2}{*}{$\begin{array}{c}\text { Germinación } \\
(\%)\end{array}$} & \multicolumn{2}{|c|}{ Plántulas germinadas } \\
\hline & & & Verde & Morado & & Sin cruza $(\%)$ & Con cruza $(\%)$ \\
\hline 1 & 353 & 278 & 278 & 0 & 78,75 & 100,00 & 0,000 \\
\hline 2 & 562 & 484 & 483 & 1 & 86,12 & 99,79 & 0,207 \\
\hline 3 & 174 & 165 & 165 & 0 & 94,83 & 100,00 & 0,000 \\
\hline 4 & 1.160 & 892 & 891 & 1 & 76,90 & 99,89 & 0,112 \\
\hline 5 & 800 & 697 & 694 & 3 & 87,13 & 99,57 & 0,430 \\
\hline Total & 3.049 & 2.516 & 2.511 & 5 & 82,52 & 99,80 & 0,199 \\
\hline
\end{tabular}

* En el punto 6 no prosperó ninguna de la plantas transplantadas pues se limpiaron los bordes del camino donde se sembraron, por lo que no hubo semilla para evaluar la alogamia.

Cuadro 3. Porcentaje de alogamia en el ensayo de flujo de genes entre frijol blanco y frijol silvestre costarricense. Quircot, Cartago, Costa Rica. 2007.

\begin{tabular}{cccccccc}
\hline \multirow{2}{*}{ Sitio* } & \multirow{2}{*}{ Semillas } & \multirow{2}{*}{$\begin{array}{c}\text { Plántulas } \\
\text { germinadas }\end{array}$} & \multicolumn{2}{c}{ Hipocotilo } & & Germinación & \multicolumn{2}{c}{ Plántulas germinadas } \\
& & Verde & Morado & $(\%)$ & & Sin cruza (\%) & Con cruza $(\%)$ \\
\hline $\mathbf{1}$ & 110 & 99 & 99 & 0 & 90,00 & 100,00 & 0,00 \\
$\mathbf{2}$ & 185 & 179 & 179 & 0 & 96,76 & 100,00 & 0,00 \\
$\mathbf{5}$ & 233 & 219 & 219 & 0 & 93,99 & 100,00 & 0,00 \\
$\mathbf{6}$ & 8 & 7 & 7 & 0 & 87,50 & 100,00 & 0,00 \\
Total & $\mathbf{5 3 6}$ & $\mathbf{5 0 4}$ & $\mathbf{5 0 4}$ & $\mathbf{0}$ & $\mathbf{9 4 , 0 3}$ & $\mathbf{1 0 0 , 0 0}$ & $\mathbf{0 , 0 0}$ \\
\hline
\end{tabular}

* En los puntos 3 y 4 las plantas transplantadas murieron debido a las condiciones climáticas imperantes, por lo que no hubo semilla para evaluar la alogamia.

En general, el porcentaje de alogamia determinado en Quircot fue mayor al obtenido en Alajuela. Una de las razones es que en Quircot se contó con polinizadores más eficientes como los chiquizá; que son atraídos por otras especies de Phaseolus de polinización abierta que conviven en el lugar como $P$. polyantus y $P$. coccineus, pero que una vez en el sitio no discriminan a la hora de polinizar, según indica Gepts et al. (2000). Por otro lado, en Quircot se contó con una mayor cantidad y cercanía de plantas de frijol silvestre con respecto a las plantas receptoras de polen (Vainica de Palo). Otro de los factores importantes que pudo influir, es que la alogamia también está ligada al frijol silvestre que se emplee como donante de polen, como se desprende del estudio de Triana et al. (1993), quienes encontraron diferencias en el cruzamiento natural según el origen del frijol silvestre empleado.

Los porcentajes de alogamia obtenidos en Quircot y Alajuela, en general, son más bajos que los determinados por Triana et al. (1993) en Cerrito, Valle, Colombia (1,5\% en promedio) y por Gepts et al. (2000) en Sierra Norte, Puebla, México (20 - $55 \%$ ), quienes también midieron el cruzamiento natural en ensayos con frijoles silvestres. Sin embargo, no se alejan mucho de los encontrados en ensayos con cultivares comerciales realizados en Costa Rica por Pinchinat (1967), quien obtuvo un $0,10 \%$ de cruzamiento promedio en su trabajo; por Alan y Moh (1966) en Alajuela, quienes encontraron una alogamia máxima de $0,20 \%$ y por Chaves et al. (2003 y 20074) quienes determinaron 
un promedio de 0,029\% de cruzamiento natural en ensayos similares realizados en Alajuela y Fraijanes del 2002 al 2006. Las diferencias observadas entre los distintos trabajos, parecen provenir de las variaciones en la metodología empleada para obtener la alogamia. Por ejemplo, Gepts et al. (2000) determinaron el porcentaje de alogamia mediante técnicas moleculares y midieron los eventos acumulados de cruzamiento natural durante muchos años, de ahí los porcentajes tan elevados que obtuvieron (20-55\%).

Además de la metodología empleada, otros factores como la población y tipo de polinizadores, el origen del frijol silvestre empleado, el color de las flores de los padres involucrados, la estructura de los receptores de polen, las condiciones agroecológicas presentes, y las condiciones propias de cada sitio, pueden influir en porcentaje de alogamia. En la investigación efectuada por Triana et al. (1993), se emplearon como padres donantes de polen tres frijoles silvestres de distinto origen: mesoamericano, del sur y del norte de los Andes; estos últimos, por presentar porcentajes de alogamia relativamente altos $(0,43-8,62 \%)$, tanto entre los receptores de polen de su acervo como con los de los de otra procedencia, elevan el promedio de alogamia encontrado. Del mismo trabajo, también se desprende que entre frijoles de origen mesoamericano el rango de cruzamiento natural varió desde 0,07 hasta $1,15 \%$; por lo que los valores encontrados en Costa Rica se encuentran dentro de este rango en el caso de Quircot o se acercan a su nivel inferior en el caso de Alajuela.

En esta investigación se trató de simular lo que ocurriría en siembras comerciales cerca de poblaciones de frijoles silvestres. La información obtenida servirá para el desarrollo de protocolos de seguridad en el país y en los trópicos, ante la potencial siembra de transgénicos. Además, constituye una evidencia de como se puede generar nueva diversidad genética natural, en campos de agricultores que siembran frijol común aledaño a poblaciones de frijol silvestre.

\section{AGRADECIMIENTOS}

A los señores Célimo Navarro y Neftalí Durán, productores de frijol y socios de la Cooperativa Rosales, por su colaboración durante la realización de este trabajo.

\section{LITERATURA CITADA}

Alan, J; Moh, C. 1966. Determinación del porcentaje de cruzamiento natural en el frijol común (Phaseoulus vulgaris L.) en Alajuela, Costa Rica. Turrialba 16(2):156-158.

Araya, R; González, W; Camacho, F; Sánchez, P; Debouck, D. 2001. Observation on the geographic distribution, ecology and conservation status of several Phaseolus bean species in Costa Rica. Genet. Resources Crop Evol. 48:221-232.

Araya, R; Debouck, D. 2003. Observaciones sobre poblaciones de frijol silvestre (Phaseolus vulgaris L.) en Costa Rica. In: Revista Agronomía Mesoamericana ed. VII Reunión Anual del Sector Frijolero de Costa Rica. Santo Domingo, Heredia. p. 29-34.

Araya R; Chaves, N; Debouck D. 2004. Flujo de genes entre variedades criollas de frijol y frijol silvestre. Informe anual 2004 del proyecto "Gene Flow Analysis for Assessing the Safety of Bio-Engineered Crops in the Tropics". Vicerrectoría de Investigación, Universidad de Costa Rica. Alajuela, Costa Rica. 36 p.

Bliss, F. 1980. Common bean. In: W. Ferh, H. Hadley eds. Hybridization of crops plants. Wisconsin, USA. American Society of Agronomy and Crop Science. p. 273-284.

Brunner, B; Beaver, J. 1989. Estimation of outcrossing of the common bean in Puerto Rico. Hort Science 24(4):669-771.

Chaves, N; Araya, R; Debouck, D. 2003. Polinización natural del frijol común en Costa Rica. In: VII Reunión Anual del Sector Frijolero de Costa Rica. Santo Domingo, Heredia. p. 35-40.

Debouck, D; Araya, R; Ocampo, R; González, W. 1989. Collecting Phaseolus in Costa Rica. FAO/IBPGRI Plant Genet. Resources Newsl. 78/789:44-46.

Ferreira, J; Álvarez, M; Fueyo, M; Roca, A; Giraldez, R. 2000. Determination of the outcrossing rates of Phaseolus vulgaris L. using seed protein markers. Euphytica 113:259-263.

Free, J. 1966. The pollination of beans Phaseolus multiflorus and Phaseolus vulgaris by honeybees. J. Apic. Res. 5(2):87-91.

Gepts, P; González, A; Papa, R; Acosta, J; Wong, A; Delgado, A. 2000. Outcrossing in Mexican wild and domesticated populations of common bean. Annual Rept. Bean Improvement Coop. 43:25-26. 
González, R; Araya, R; Gaitán, E; Debouck, D. 2004. Wild common bean in the Central Valley of Costa Rica: ecological distribution and molecular characterization. Agronomía Mesoamericana 15(2):145-153.

Gutiérrez, M; Soto, D; Alpízar, M. 1997. Cuarenta años de observaciones meteorológicas en la Estación Experimental Fabio Baudrit Moreno. Boletín Técnico Estación Experimental Fabio Baudrit Moreno (BOLTEC) 30(2):1-14.

Ibarra, F; Ellstrand, N; Giles, J. 1996. Multiple paternity in common bean (Phaseolus vulgaris L., Fabaceae). American Journal of Botany 83(6):749-758.

León, J. 1987. Papilionaceas. In: Botánica de los cultivos tropicales. San José, Costa Rica. Instituto Interamericano de Cooperación para la Agricultura. p. 265-299.

Miranda, S. 1971. Cruzamiento natural en frijol. Agricultura Técnica en México 3(2):48-52.

Ortega, S. 1974. Polinización cruzada natural de la caraota (P. vulgaris L.) en Venezuela. Agronomía Tropical 24(1):27-32.
Pinchinat, A. 1967. Cruzamiento natural en el frijol común en Costa Rica. In: $7^{\text {a }}$ Reunión Latinoamericana de Fitotecnia. Maracay, Venezuela. 17-23.

Regina, M; Gonçalves, M; Sacpim, C; Vidigal, P; Miglioranza, E. 2000. Natural outcrossing rates of bean cultivars (Phaseolus vulgaris L.). Ann. Rep. Improvement Coop. 43:195-195.

Stoetzer, H. 1984. Natural cross-polinization in bean in Ethiopia. Ann. Rep. Bean Improvement. Coop. 27:99100.

Triana, B; Iwagana, M; Rubiano, H; Andrade, M. 1993. A study of allogamy in wild Phaseolus vulgaris. Annu. Rep. Bean Improvement Coop. 36:20-21.

Tucker, C; Harding, J. 1975. Outcrossing in common bean Phaseolus vulgaris L. Amer. Soc. Hort. Sci. 100(3):283-285.

Wells, W; Isom, W; Waines, J. 1988. Outcrossing rates of six common bean lines. Crop Science 28:177178. 